\title{
Mead acid inhibits the growth of KPL-1 human breast cancer cells in vitro and in vivo
}

\author{
YUICHI KINOSHITA ${ }^{1}$, KATSUHIKO YOSHIZAWA ${ }^{1}$, KEI HAMAZAKI ${ }^{2}$, YUKO EMOTO ${ }^{1}$, TAKASHI YURI ${ }^{1}$, \\ MICHIKO YUKI $^{1}$, NOBUAKI SHIKATA ${ }^{3}$, HIROSHI KAWASHIMA ${ }^{4}$ and AIRO TSUBURA ${ }^{1}$ \\ ${ }^{1}$ Department of Pathology II, Kansai Medical University, Hirakata, Osaka 573-1010; ${ }^{2}$ Department of Public Health, \\ Faculty of Medicine, University of Toyama, Sugitani, Toyama 930-0194; ${ }^{3}$ Division of Diagnostic Cytopathology \\ and Histopathology, Kansai Medical University Takii Hospital, Moriguchi, Osaka 570-8507; \\ ${ }^{4}$ Institute for Health Care Science, Suntory Wellness Ltd., Shimamoto, Osaka 618-8503, Japan
}

Received June 18, 2014; Accepted July 17, 2014

DOI: $10.3892 /$ or.2014.3390

\begin{abstract}
The effects of mead acid (MA; 5,8,11-eicosatrienoic acid) on the suppression of breast cancer cell growth and metastasis were examined in vitro and in vivo by using the KPL-1 human breast cancer cell line. MA suppressed KPL-1 cell growth in culture with an $\mathrm{IC}_{50}$ value of $214.2 \mu \mathrm{M}(65.7 \mu \mathrm{g} / \mathrm{ml})$ for $72 \mathrm{~h}$, and MA significantly suppressed transplanted KPL-1 tumor growth (tumor volume and tumor weight: $872 \pm 103 \mathrm{~mm}^{3}$ and $1,000 \pm 116 \mathrm{mg}$ vs. $376 \pm 66 \mathrm{~mm}^{3}$ and $517 \pm 84 \mathrm{mg}$ ) and regional (axillary) lymph node metastasis (67\%, 10/15 vs. $10 \%$, $1 / 10$ ) in female athymic mice fed an MA-rich diet for 8 weeks. Tumor suppression was due to the suppression of cell proliferation. In ELISA, although vascular endothelial growth factor (VEGF) levels were unchanged, VEGF receptor (VEGFR)1 and VEGFR2 levels were significantly decreased after treatment with a 214.2- $\mu \mathrm{M}$ dose of MA for $72 \mathrm{~h}$; E-cadherin levels were unchanged. As VEGF, VEGFR1 and VEGFR2 expression was co-localized in KPL-1 cells, the mechanism leading to cell growth suppression was VEGF signaling directly to KPL-1 cells by an autocrine process. In contrast, MA did not influence angiogenesis. The mechanisms of action were through VEGF signaling directly to cancer cells.
\end{abstract}

\section{Introduction}

Breast cancer is one of the most common types of cancer in industrial countries. Epidemiological studies indicate that the incidence and mortality of breast cancer is up to 5-fold higher in Western countries than in some Asian countries, and Asian migrants to the USA eventually acquire the breast cancer

Correspondence to: Professor Airo Tsubura, Department of Pathology II, Kansai Medical University, Hirakata, Osaka 573-1010, Japan

E-mail: tsubura@hirakata.kmu.ac.jp

Key words: breast cancer, KPL-1 cells, mead acid, VEGF, VEGF receptors, E-cadherin incidence of their host country, suggesting the importance of environmental factors (1). Among the environmental factors, it is clear that dietary exposure influences breast cancer risk, and particularly dietary intake of fat may play an important role in the genesis of breast cancer (2-5). Not only the amount of fat consumption, but also the type of dietary fat may have different effects on breast carcinogenesis. Long-chain polyunsaturated fatty acids (PUFAs) have different effects on mammary tumorigenesis based on the double bond position (6-8). The first double bond located at the 3rd, 6th or 9th carbon from the terminal methyl group of a fatty acid is called an n-3, n- 6 or n-9 series fatty acid, respectively. Epidemiological studies and preclinical data indicate a positive association between dietary n-6 PUFA and breast cancer risk, while n-3 PUFA possesses chemopreventive properties $(9,10)$. n-3 PUFAs such as eicosapentaenoic acid (EPA; 20:5n-3) suppress human breast cancer cell growth (11). Among n-3 PUFAs, docosahexaenoic acid (DHA; 22:6n-2) suppresses mammary carcinogenesis more effectively than EPA (7). In contrast, n-6 PUFAs such as linoleic acid (LA; 18:2n-6) and arachidonic acid (AA; 20:4n-6) promote the growth of human breast cancer cells $(11,12)$. The typical American high-fat diet contains high levels of LA (13). Olive oil rich in oleic acid (OA; 18:1n-9) suppresses mammary carcinogenesis (14). However, it is difficult to determine if the effects of OA on experimental carcinogenesis are due to specific biochemical properties of OA or simply due to the substitution for n-6 PUFA (15). The role of n-9 PUFA in relation to breast cancer has not been studied in detail.

Mead acid (MA; also referred to as 5,8,11-eicosatrienoic acid), which was first characterized by James F. Mead, is a carboxylic acid with a 20-carbon chain and three methyleneinterrupted cis double bonds, in which the first double bond is located at the ninth carbon from the terminal methyl group of a fatty acid (20:3n-9; Fig. 1). MA is a minor constituent of plasma and tissue in adult mammals. Elongation and desaturation of OA take place to form MA when n-6 and n-3 essential fatty acids, particularly LA, are deficient. Therefore, MA elevation in the blood is an indication of essential fatty acid deficiency. MA is found in large quantities in cartilage; MA decreases osteoblastic activity for the maintenance of cartilage to prevent ossification and suppresses angiogenesis 


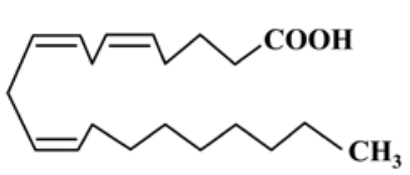

Figure 1. Chemical structure of mead acid (5,8,11-eicosatrienoic acid; 18:3n-9). The number before the colon indicates the number of carbon atoms, and the number after the colon indicates the number of double bonds. The conformation of the double bond is cis in configuration, and the first double bond is located at the 9 th carbon from the terminal methyl group.

to maintain avascular status $(16,17)$. Angiogenesis plays an important role in the growth of breast cancer (18), and antiangiogenic agents [inhibitors of vascular endothelial growth factor (VEGF)] and the VEGF receptor (VEGFR) may be promising targets for breast cancer control $(19,20)$. The loss of cell adhesion is related to cancer invasion and metastasis. MA is related to the expression of the cell-cell adhesion molecule E-cadherin in human cancer cell lines including breast cancer cells $(21,22)$. E-cadherin-mediated signaling can influence invasive and metastatic behavior $(23,24)$. VEGF and/or E-cadherin signaling may modulate breast cancer growth at the primary site, and invasion and metastasis in the MA-rich condition. In addition, leukotriene $\mathrm{B}_{4}\left(\mathrm{LTB}_{4}\right)$ enhances tumor growth in human cancer cells including breast cancer cells $(25,26)$. Dietary supplementation with MA suppresses $\mathrm{LTB}_{4}$ in rats $(27,28)$. Moreover, a nested case-control study revealed an inverse association between MA and breast cancer risk as well as overall cancer risk (29); in the present study, neither the n-6/n-3 ratio nor AA intake correlated with breast cancer risk. Collectively, MA may exert cancer preventive properties. However, MA shows different effects on different types of cancer cells $(21,22)$. The present study was designed to explore the effect of MA on KPL-1 human breast cancer cell growth and metastasis. The mechanisms of action were investigated based on VEGF and E-cadherin signaling and the modulation of fatty acid composition.

\section{Materials and methods}

Cell line. KPL-1 is a human breast cancer cell line established from the malignant effusion of a breast cancer patient (30). This cell line was derived from a patient with recurrent breast cancer that appeared during postsurgical adjuvant chemoendocrine therapy including tamoxifen and medroxyprogesterone acetate. The KPL-1 cell line is estrogen receptor (ER)-positive, progesterone receptor (PgR)-negative, and human epidermal growth factor receptor-2 (HER2)-negative (luminal A subtype) (31). Xenograft athymic mice injected with KPL-1 cells often develop lymph node metastasis (30). KPL-1 cells were cultured in Dulbecco's modified Eagle's medium (DMEM; Sigma, St. Louis, MO, USA) with $10 \%$ fetal bovine serum (FBS; Gibco-BRL, Grand Island, NY, USA) in $5 \% \mathrm{CO}_{2} / 95 \%$ humidified air at $37^{\circ} \mathrm{C}$.

MA preparation. MA used for in vitro experiments was purchased from Sigma and dissolved to $5 \mathrm{mg} / 500 \mu 1(32.6 \mathrm{mM})$ in ethanol and stored at $-30^{\circ} \mathrm{C}$. MA was diluted in DMEM containing $10 \%$ FBS to achieve final concentrations of 16.25, $32.5,75,150$ and $300 \mu \mathrm{M}$.
Table I. Composition of experimental diets.

\begin{tabular}{lrr}
\hline & MA diet & Control diet \\
\hline Casein & 20 & 20 \\
DL-methionine & 0.3 & 0.3 \\
Cornstarch & 43 & 43 \\
$\alpha$-cornstarch & 12 & 12 \\
Sucrose & 10 & 10 \\
Cellulose & 5 & 5 \\
AIN-76 mineral mix & 3.5 & 3.5 \\
AIN-76 vitamin mix & 1 & 1 \\
Choline bitartrate & 0.2 & 0.2 \\
SUNTGM33 & 5 & 0 \\
Olive oil & 0 & 5 \\
\hline
\end{tabular}

Values are expressed in $\mathrm{g} / 100 \mathrm{~g}$ diet. MA, mead acid.

MTT assay. KPL-1 cells were seeded at $2 \times 10^{3}$ cells/well in 96-well plates in DMEM with $10 \%$ FBS. The cells were treated with ethanol (final concentration, $0.9 \%$ ) or the indicated concentration of MA for up to $72 \mathrm{~h}$. Cell proliferation was monitored by the 3-(4,5-dimethylthiazol-2-yl)-2,5-diphenyl tetrazolium bromide (MTT) assay as previously described (32), and $\mathrm{IC}_{50}$ value was calculated.

Animal experiments. Animals were housed in groups of four or five in plastic cages with paper bedding (Paper Clean, SLC, Hamamatsu, Japan) in a specific pathogen-free room maintained at $22 \pm 2{ }^{\circ} \mathrm{C}$ and $60 \pm 10 \%$ relative humidity with a 12-h light/dark cycle (lights on at 8:00 AM and lights off at 8:00 PM). The mice were randomly divided into two groups, the control diet group $(n=15)$ and the MA diet group $(n=10)$. Both experimental diets were modifications of the AIN-76 diet (33) and contained the same amount of nutrients but had different fatty acid compositions (Table I). The MA diet contained 5\% SUNTGM33 (a kind gift from Suntory Wellness, Tokyo, Japan), which contains $48.0 \%$ MA (Table II). SUNTGM33 is a microbial oil obtained by fungal fermentation (34). Olive oil purchased from Nacalai Tesque (Kyoto, Japan) was used for the control diet. The fatty acid compositions of SUNTGM33 and olive oil are listed in Table II. Each experimental diet was formulated by Oriental Yeast (Tokyo, Japan). Four-week old female athymic BALB/c mice purchased from Charles River Japan (Kyoto, Japan) were fed either a control or MA diet starting at 4 weeks of age. In comparison to the control diet, the MA diet for 8 days starting at 4 weeks of age did not cause weight gain. Therefore, the MA diet group was switched to the control diet for 4 successive days to accelerate weight gain; thereafter, the MA diet group was treated with a cyclic feeding regime of 5 days on the MA diet followed by 2 days on the control diet throughout the experiment. The control group was treated with the control diet throughout the experiment. Schematic representation of the in vivo experiment is shown in Fig. 2. At 6 weeks of age, both groups were inoculated with $2.5 \times 10^{5} \mathrm{KPL}-1$ cells in $100 \mu \mathrm{l}$ DMEM supplemented with $10 \%$ FBS into the thoracic mammary fat pad (MA diet group was on the third day of MA diet). During the experiment, the dose of 
Table II. Fatty acid composition of SUNTGM33 and olive oil.

\begin{tabular}{lrr}
\hline Fatty acid composition (\%) & SUNTGM33 & Olive oil \\
\hline Myristic acid (14:0) & 0.12 & 0.00 \\
Palmitic acid (16:0) & 3.35 & 10.88 \\
Palmitoleic (16:1n-7) & 0.00 & 0.85 \\
Stearic acid (18:0) & 4.96 & 3.32 \\
Oleic acid (18:1n-9) & 25.10 & 74.71 \\
Vaccenic acid (18:1n-7) & 0.14 & 1.89 \\
Linoleic acid (18:2n-6) & 0.42 & 6.90 \\
a-Linolenic acid (18:3n-3) & 0.00 & 0.68 \\
Arachidic acid (20:0) & 0.00 & 0.46 \\
Gondoic acid (20:1n-9) & 4.95 & 0.31 \\
Mead acid (20:3n-9) & 48.02 & 0.00 \\
Arachidonic acid (20:4n-6) & 1.23 & 0.00 \\
Eicosapentaenoic acid (20:5n-3) & 0.47 & 0.00 \\
Behenic acid (22:0) & 2.15 & 0.00 \\
Lignoceric acid (24:0) & 5.34 & 0.00 \\
Nervonic acid (24:1n-9) & 2.42 & 0.00 \\
Total n-9 & 80.49 & 75.02 \\
Total n-3 & 0.47 & 0.68 \\
Total n-6 & 1.65 & 6.90 \\
n-6/n-3 & 3.53 & 10.19 \\
Total SFA & 15.91 & 14.66 \\
Total MUFA & 32.61 & 77.76 \\
Total PUFA & 50.15 & 7.58 \\
\hline SFA & & \\
\hline
\end{tabular}

SFA, saturated fatty acid; MUFA, monounsaturated fatty acid; PUFA, polyunsaturated fatty acid.

diet ingested, body weight and locally growing tumor volumes were measured once per week. Tumor volume was calculated by using the standard formula: width ${ }^{2} \mathrm{x}$ length $\mathrm{x} 0.5$. Thirtyseven days after tumor cell inoculation (fifth day on MA diet), body weight was measured, and bromodeoxyuridine (BrdU; Invitrogen, Camarillo, CA, USA) was injected $(50 \mathrm{mg} / \mathrm{kg}$ animal body weight) via the abdominal cavity, blood was sampled and then animals were sacrificed by exsanguination from aortic transection. At autopsy, all organs were examined macroscopically, and the primary tumors and local axillary lymph nodes were examined histologically; half of the primary tumor was snap frozen and used for fatty acid analysis. Tissues were fixed in $10 \%$ neutral buffered formalin, embedded in paraffin, and stained with hematoxylin and eosin (H\&E). The study protocol and animal procedures were approved by the Animal Care and Use Committee of Kansai Medical University (permit no. 13-060). Throughout the experiments, animals were cared for in accordance with the Guidelines for Animal Experimentation of Kansai Medical University.

Fatty acid analysis. The fatty acid composition of the total phospholipid fraction of serum was determined. Total lipids were extracted by the method of Bligh and Dyer (35). The total phospholipid fraction was separated by thin-layer chromatography. For an internal standard, 1,2-diheptadecanoyl-sn-glycero-3-phosphocholine (Avanti Polar Lipids,

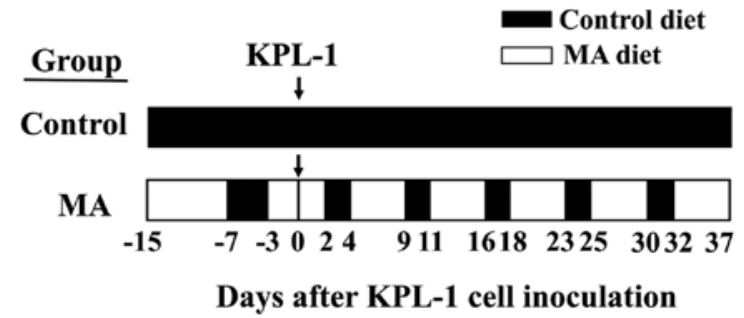

Figure 2. Schematic representation of the in vivo experimental protocol.

Inc., Alabaster, AL, USA) was added. Total phospholipid fractions were transmethylated with $\mathrm{HCl}$-methanol and then the fatty acid composition was analyzed by gas chromatography (GC-2014; Shimadzu Corporation, Kyoto, Japan) with a capillary column DB-225 $(0.25 \mathrm{~mm}$ x $30 \mathrm{~m}$ x $0.25 \mu \mathrm{M}$; J\&M Scientific, Folsom, CA, USA). The entire system was controlled with gas chromatography software (GCsolution; Shimadzu Corporation). The fatty acid composition of the total lipid fraction of KPL-1 tumors was determined. In brief, frozen tumor tissues were thawed, minced and homogenized three times in $8 \mathrm{ml}$ chloroform-methanol (2:1) by a polytron homogenizer (Kinematica, Lucerne, Switzerland) for $10 \mathrm{sec}$. The fatty acid analysis of total lipids in the tumor was performed by the same method as previously mentioned $(35,36)$.

Microvessel density and cell kinetics. Microvessel density of primary KPL-1 tumors was evaluated by anti-CD34 antiserum (Abcam, Cambridge, UK). The cell kinetics (cell proliferation and cell death) in primary KPL-1 tumors were evaluated. Cell proliferation was evaluated by anti-BrdU antibody (clone B44, 1:50; Becton-Dickinson, Franklin Lakes, NJ, USA) by using an LSAB staining kit (Dako, Glostrup, Denmark). Cell death was evaluated by anti-phospho-histone H2A.X ( $\gamma$-H2AX) antibody (Ser139, 1:100; Cell Signaling, Danvers, MA, USA), an immunomarker of the DNA damage response. Each slide was scanned with a high-resolution digital slide scanner (NanoZoomer 2.0 Digital Pathology; Hamamatsu Photonics, Hamamatsu, Japan) to prepare digital images. The ndpi image files were opened in color mode with NDP.view software (Hamamatsu Photonics). The images were changed to jpeg files at $\times 40$ magnification in five randomly selected areas within each tumor that were used to analyze immunohistochemical staining (37-39).

CD34, VEGF, VEGFR1, VEGFR2 and E-cadherin immunohistochemistry. Cell blocks were prepared from KPL-1 cells cultured with or without $214.2 \mu \mathrm{M}$ MA for $72 \mathrm{~h}\left(\mathrm{IC}_{50}\right.$ value for 72 h). Cell blocks were prepared from cultured KPL-1 cells; cells were centrifuged at 1,000 rpm for $5 \mathrm{~min}$, and cell pellets were fixed in $10 \%$ neutral buffer formalin and embedded in paraffin. Antisera used to detect CD34, VEGF, VEGFR1, VEGFR2 and E-cadherin were anti-CD34 antiserum (1:20; Abcam), anti-VEGF antiserum (1:50), anti-VEGFR1 antiserum (1:500) (both from Santa Cruz Biotechnology, Santa Cruz, CA, USA) and anti-VEGFR2 antiserum (1:400) (Cell Signaling Technology, Danvers, MA, USA), respectively, by using an LSAB staining kit (Dako), and anti-E-cadherin antibody (NCH38 ready to use) by using Histofine MAX-PO (both from Nichirei Biosciences, Tokyo, Japan) according to 


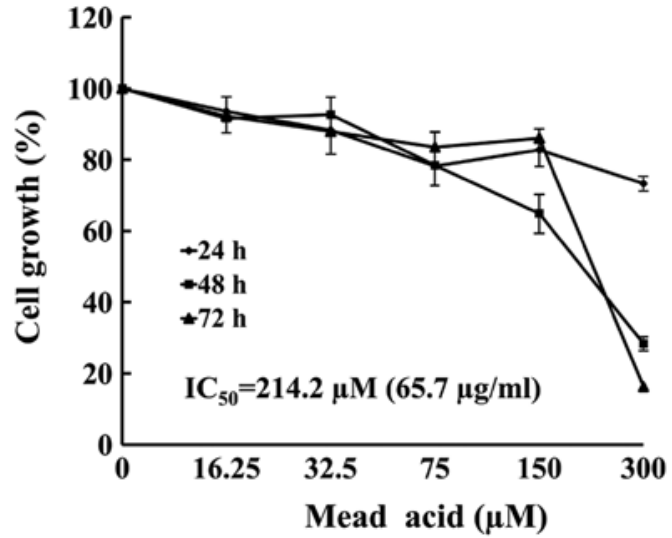

Figure 3. Growth inhibition curves of KPL-1 cells in vitro caused by mead acid (MA). MA was diluted in $10 \%$ ethanol, stored at $4{ }^{\circ} \mathrm{C}$, and diluted in DMEM with $10 \%$ FBS to the final concentration immediately before use. KPL-1 cells were plated on 96-well plates at $2 \times 10^{3}$ cells/well, and cell proliferation was determined by MTT assay. The $\mathrm{IC}_{50}$ value was $214.2 \mu \mathrm{M}$. Data are means \pm SEM of 3 independent experiments.

the manufacturer's instructions. The reaction products were visualized with 3-3'-diaminobenzidine tetrahydrochloride. CD34 immunohistochemistry was applied for angiogenesis evaluation in KPL-1 tumor grown in athymic mice, and VEGF, VEGFR1, VEGFR2 and E-cadherin immunohistochemistry, respectively, were applied in cultured KPL-1 cells in cell pellets.

Quantitation of VEGF, VEGFRI, VEGFR2 and E-cadherin. KPL-1 cells cultured with or without $214.2 \mu \mathrm{M}$ MA for $72 \mathrm{~h}$ $\left(\mathrm{IC}_{50}\right.$ value for $72 \mathrm{~h}$ ) were sampled. VEGF was quantified in the culture supernatant, and VEGFR1, VEGFR2 and E-cadherin were measured in the cell lysate. For cell lysate preparation, after washing cells with PBS (-), cell pellets were homogenized with RIPA buffer (Wako, Osaka, Japan), and the cell lysate was centrifuged at $14,000 \mathrm{rpm}$ for $15 \mathrm{~min}$ at $4^{\circ} \mathrm{C}$ to obtain supernatant containing cell lysate. Protein concentrations were measured by the DC protein assay kit (Bio-Rad, Hercules, CA, USA). VEGF, VEGFR1, VEGFR2 and E-cadherin levels were measured by enzyme-linked immunoabsorbent assay (ELISA) with a human VEGF assay kit (IL-226; IBL, Fujioka, Japan), VEGFR1 human ELISA kit (ab119613), VEGFR2 human ELISA kit (ab100665) (both from Abcam), and E-cadherin human ELISA kit (R\&D Systems, Minneapolis, MN, USA), respectively, according to the manufacturers' protocols. Each protein standard or protein purified from each group was incubated overnight at $4^{\circ} \mathrm{C}$ against VEGF or E-cadherin; $90 \mathrm{~min}$ at $37^{\circ} \mathrm{C}$ against VEGFR1; or $150 \mathrm{~min}$ at room temperature against VEGFR2. After the final colors were developed with the addition of each color reagent, absorbance was measured at $450 \mathrm{~nm}$. Cell sample concentration was calculated from a standard curve and corrected for protein concentration. The limits for detection for VEGF, VEGFR1, VEGFR2 and E-cadherin were $8,156,70$ and $39 \mathrm{pg} / \mathrm{ml}$, respectively.

Statistical analysis. Values are expressed as the means \pm standard error of the mean (SEM). Body weight, tumor volume, tumor weight, fatty acid composition, CD34-positive area and the number of BrdU- and $\gamma-\mathrm{H} 2 \mathrm{AX}$ - positive cells per $1 \mathrm{~mm}^{2}$

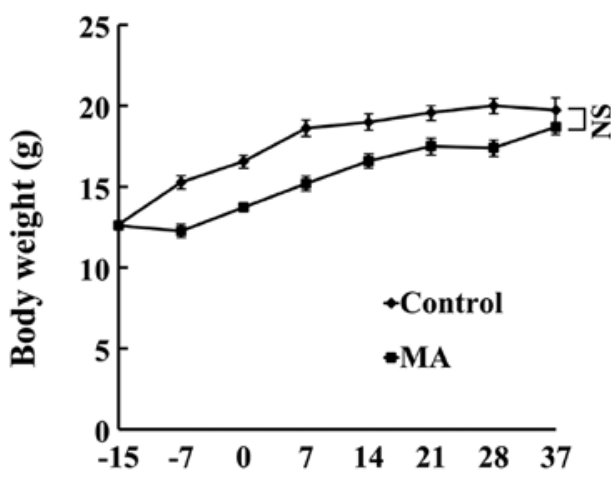

Days after KPL-1 cell inoculation

Figure 4. Body weight change in female athymic BALB/c mice fed control and mead acid (MA) diet for 8 weeks. Body weight was lighter in the MA diet group during the experiment, but the final body weight difference between the groups was not significant at the end of the experiment.

among the groups were analyzed by t-test. The incidence of metastasis was analyzed with the $\chi^{2}$ test.

\section{Results}

KPL-1 cell growth inhibition in vitro. The KPL-1 cells were treated with 5 concentrations $(16.25-300 \mu \mathrm{M})$ of MA for up to $72 \mathrm{~h}$. The MTT assay revealed that MA induced growth inhibition in a dose- and time-dependent manner (Fig. 3). The $\mathrm{IC}_{50}$ value of MA against KPL-1 cells was $214.2 \mu \mathrm{M}(65.7 \mu \mathrm{g} / \mathrm{ml})$ for a 72-h treatment.

Host animals. During the experiment, the daily dose of MA ingestion was $63-80 \mathrm{mg} / \mathrm{mouse} /$ day (mean, $74 \mathrm{mg} / \mathrm{mouse} /$ day). Body weight gain in the MA group was significantly smaller during the experiment but at the end of the experiment (eating the respective diet for 8 weeks), the difference in body weight between the MA and control diet group was not statistically significant (Fig. 4). No organs or tissues were macroscopically abnormal. Throughout the experiment, the MA diet group ingested less food than the control diet group (average, 92.1\%).

Primary KPL-1 tumor growth and metastasis. Locally growing KPL-1 tumors in the MA diet group grew slower than in the control diet group. The final tumor volume was significantly smaller (Fig. 5A) and the final tumor weight was significantly lighter (Fig. 5B) in the MA diet group as compared to the control diet group $(\mathrm{p}<0.01$ and $\mathrm{p}<0.05$, respectively). Tumor volume two days before the termination of the experiment was $872 \pm 103$ and $376 \pm 66 \mathrm{~mm}^{3}$, and the final tumor weight was $1,000 \pm 116$ and $517 \pm 84 \mathrm{mg}$ in the control and MA group, respectively. Regional (axillary) lymph node metastasis was found in both groups (Fig. 5C). Similarly, as compared with the control diet group, metastasis was significantly suppressed in the MA diet group (66.7\%: 10/15 vs. 10\%: 1/10).

Morphology and angiogenesis of KPL-1 tumor. Although the growth of KPL-1 tumors was suppressed in the MA diet group, the morphology was comparable in both groups (data 


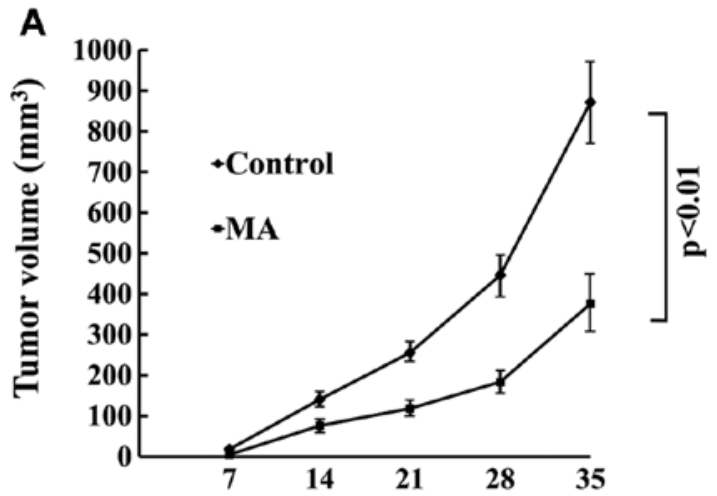

Days after KPL-1 cell inoculation
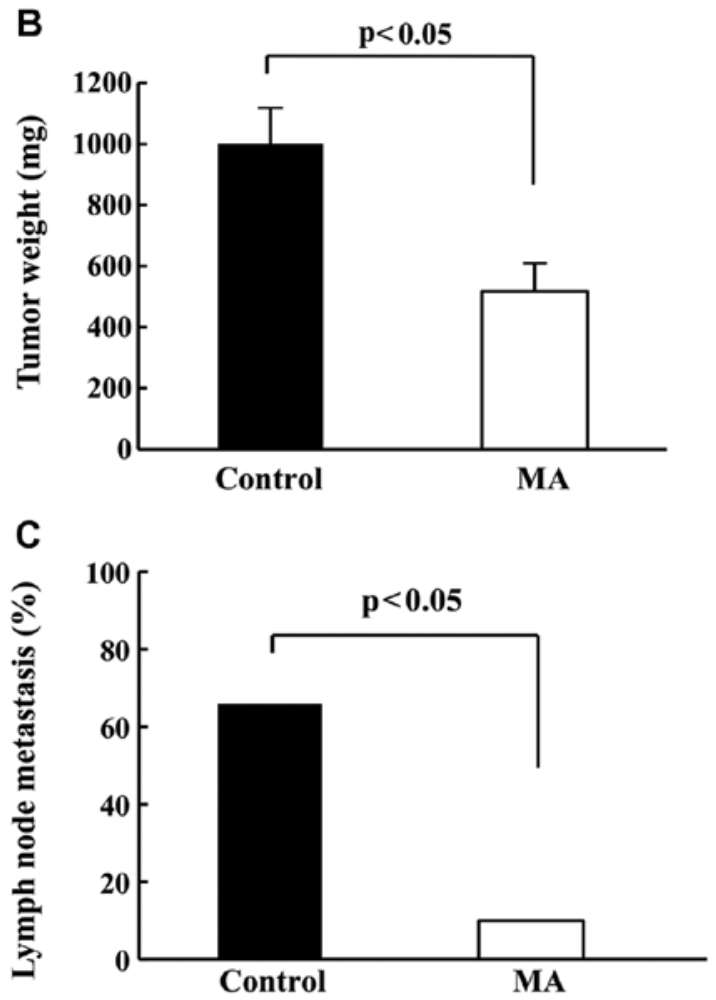

Figure 5. Effects of mead acid (MA) diet on the KPL-1 primary tumor growth at the inoculation site and axillary lymph node metastasis in female $\mathrm{BALB} / \mathrm{c}$ mice. (A) MA suppressed KPL-1 tumor growth in that the primary tumor volume was significantly smaller $(\mathrm{p}<0.01)$; (B) the final primary tumor weight was significantly lighter $(\mathrm{p}<0.05)$; and $(C)$ metastasis was significantly decreased $(\mathrm{p}<0.05)$.

not shown). The angiogenesis of KPL-1 tumors at the primary site (Fig. 6A) as well as the CD34-stained area was compatible between the control and MA diet groups (Fig. 6B).

Proliferation and apoptotic ratio of KPL-1 tumor. To compare the cell kinetics of KPL-1 tumors (cell proliferation and cell death), the number of BrdU-positive cells and $\gamma$-H2AX-positive cells per 1,000 cells in primary tumors from the control and MA diet groups of mice was compared. The proliferation and apoptotic ratios are shown in Fig. 7A and B, respectively. The proliferation ratio in the control and MA diet groups was $11.8 \pm 0.7$ and $8.7 \pm 0.9 \%$, respectively $(\mathrm{p}<0.05)$, while the apoptotic ratio in the control and MA diet groups was $8.7 \pm 1.3$ and $9.6 \pm 1.2 \%$ (not statistically significant).

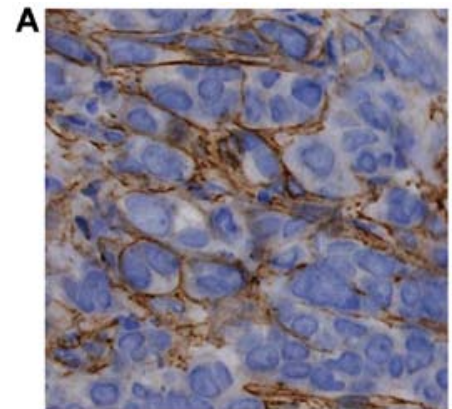

Control

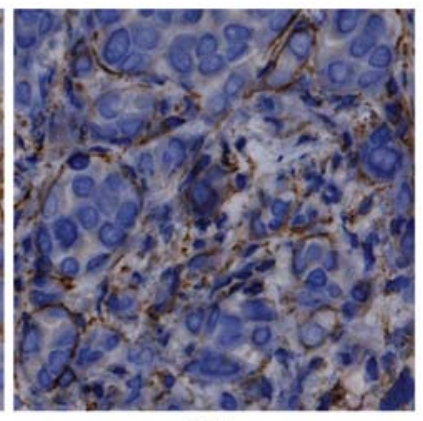

MA
B

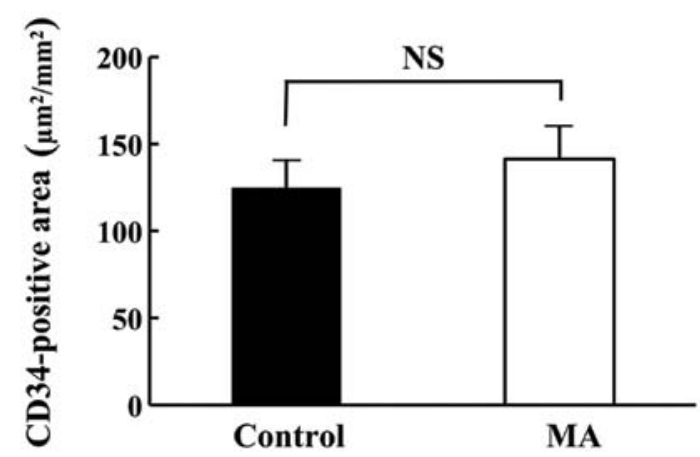

Figure 6. Vascularity of KPL-1 tumors at primary sites in the mead acid (MA) and control diet groups. (A) Vascularity and (B) microvessel density was compatible between groups (CD34 staining, respectively).
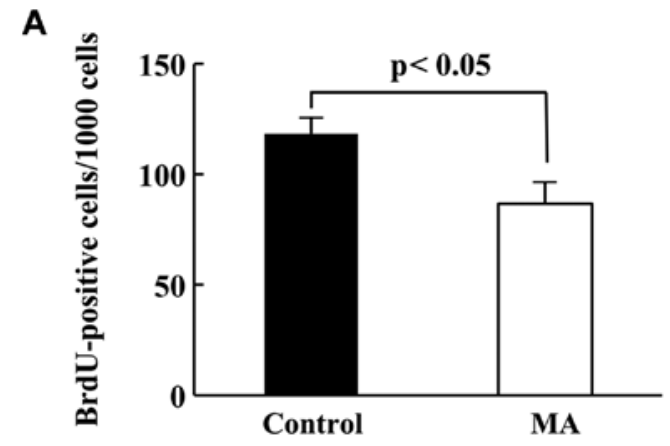

B

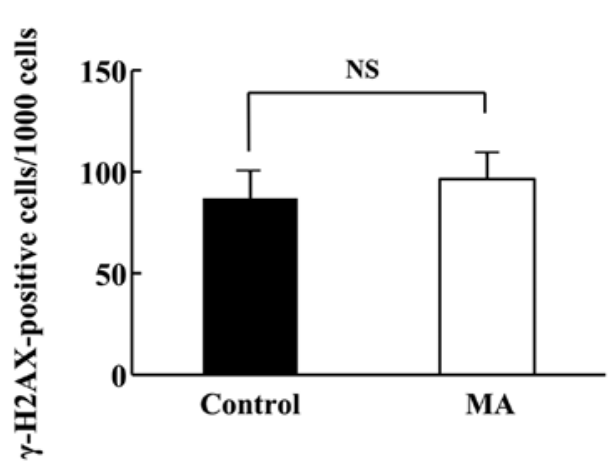

Figure 7. Effects of mead acid (MA) diet on cell kinetics in KPL-1 tumors in female athymic BALB/c mice. (A) The proliferation ratio was significantly different $(\mathrm{p}<0.05)$ between the MA diet and control diet groups, while (B) the apoptotic ratio was not significantly different between the two groups.

Fatty acid analysis. Fatty acid composition of sera and KPL-1 tumors in the control and MA diet group is shown in Fig. 8A and B, respectively. In the sera, the concentration of 
A Fatty Acid Composition of Serum

A

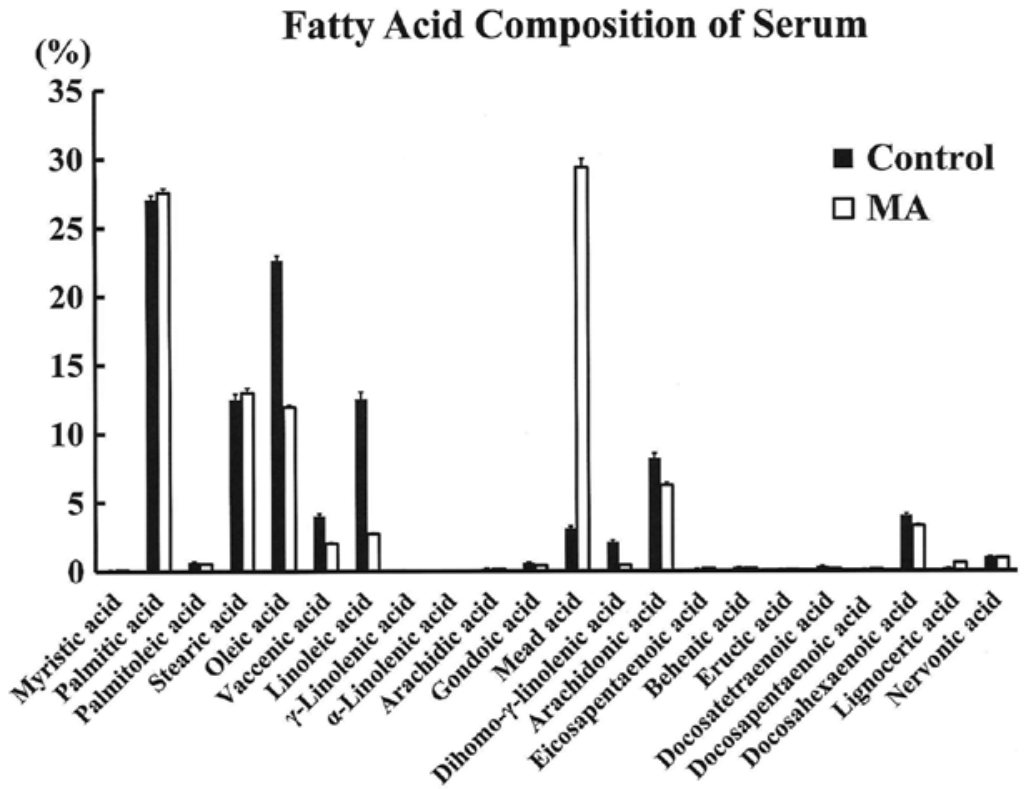

B

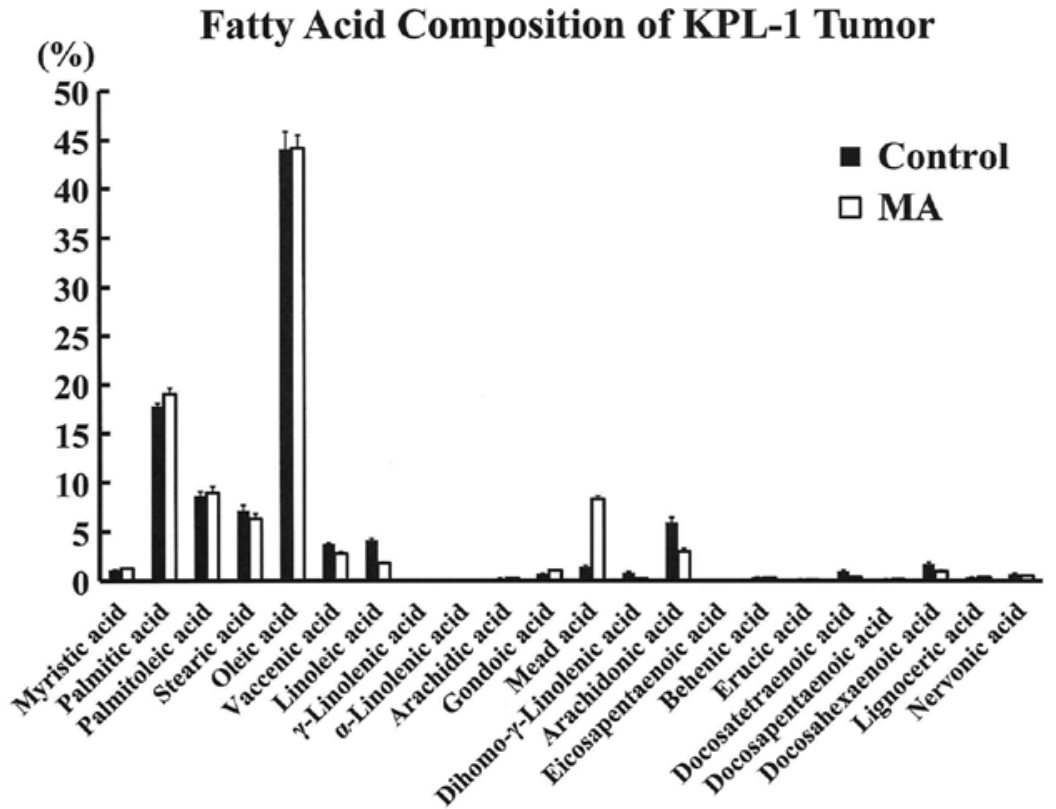

Figure 8. Comparison of fatty acid composition in female athymic BALB/c mice inoculated with KPL-1 cells and fed a mead acid (MA) diet for 8 weeks. (A) Total phospholipid fraction of the serum and (B) total lipid fraction of the KPL-1 tumor.

MA was significantly higher in the MA diet group as compared to controls (237.2 $\pm 17.6 \mathrm{vs} .23 .8 \pm 1.1 \mu \mathrm{g} / \mathrm{ml})$. In contrast, LA and AA were significantly lower in the MA diet group as compared with controls. In the KPL-1 tumor, the fatty acid profile was generally similar to that of the fatty acid composition in the serum. However, the serum OA composition was significantly higher in the control diet group, as MA was replaced by OA in this diet, while the OA concentration in KPL-1 tumors was comparable. The MA diet significantly decreased the $n-6 / n-3$ ratio in the sera and the tumors (Fig. 9).

Expression of VEGF, VEGFR1, VEGFR2 and E-cadherin in KPL-1 cells in culture. KPL-1 cells strongly expressed VEGF, VEGFR1 and VEGFR2 in the cytoplasm and E-cadherin at the cell surface. Although VEGF expression was unchanged,

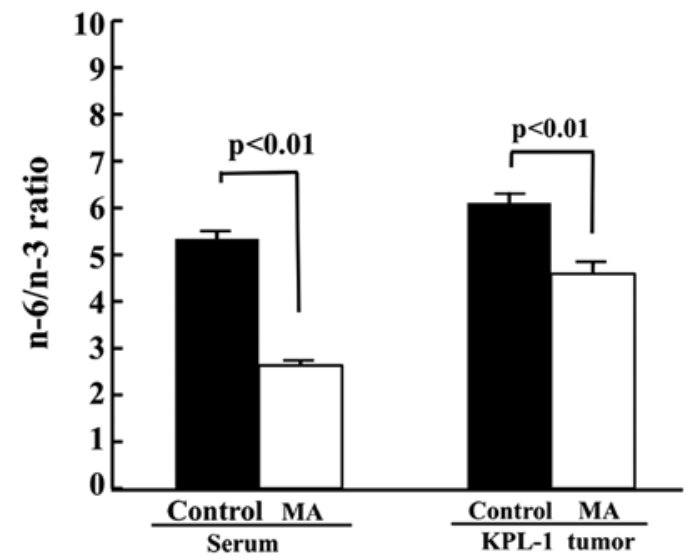

Figure 9. n-6/n-3 ratio in sera and KPL-1 tumors after mead acid (MA) diet. In sera and tumors, the MA diet significantly lowered the n-6/n-3 ratio. 


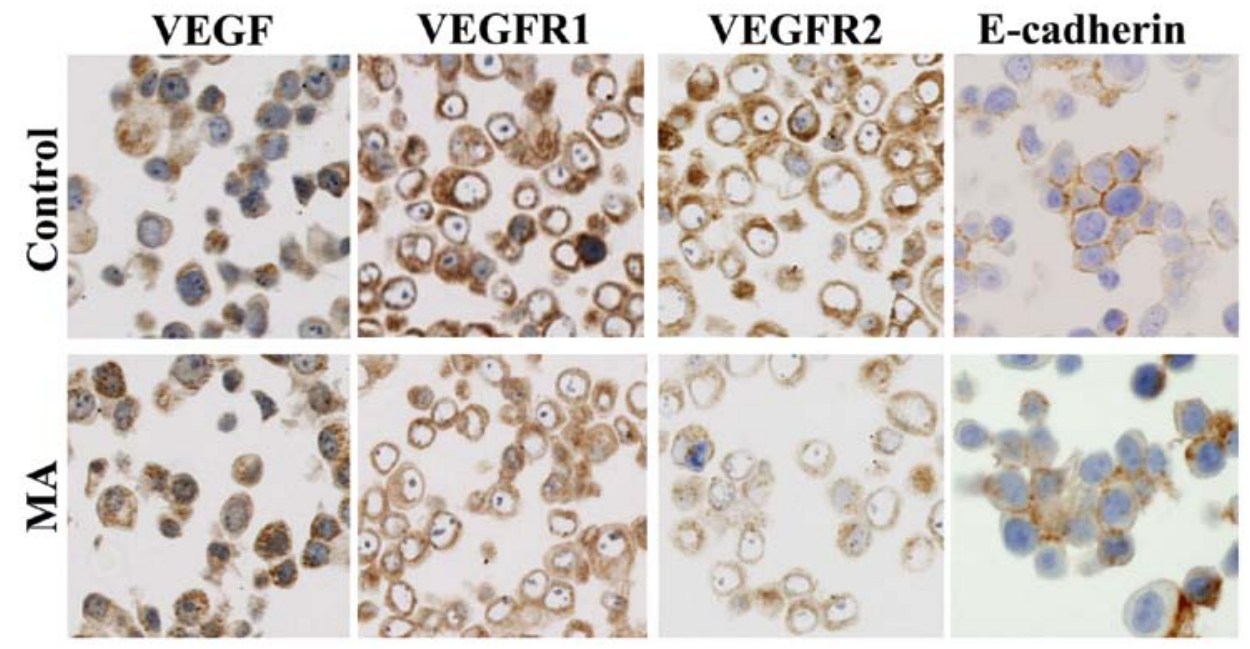

Figure 10. Immunohistochemical expression of VEGF, VEGFR1, VRGFR2 and E-cadherin in cultured KPL-1 cells cultured with or without the IC ${ }_{50}$ dose of mead acid (MA; $214.2 \mu \mathrm{M}$ ) for $72 \mathrm{~h}$. KPL-1 cells strongly expressed all four molecules examined and MA treatment tended to alter the reactivity.

A

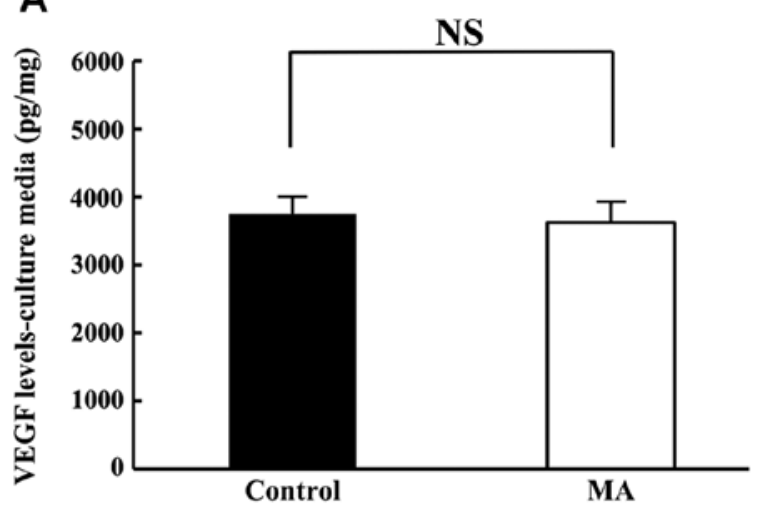

C

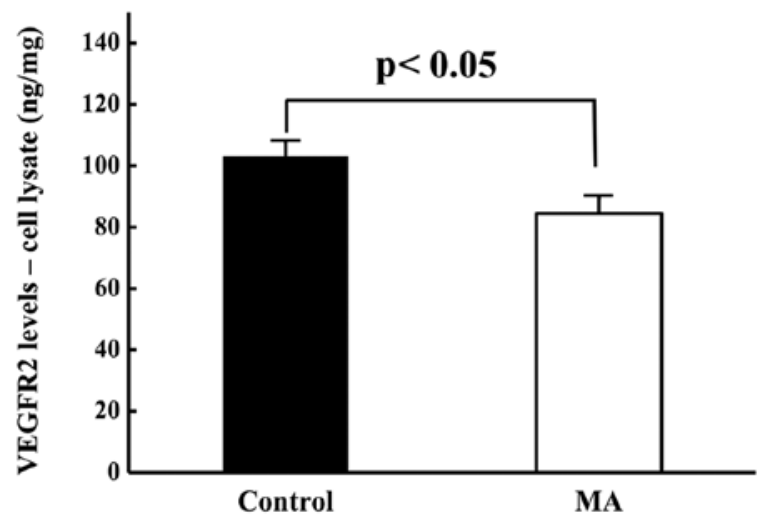

B

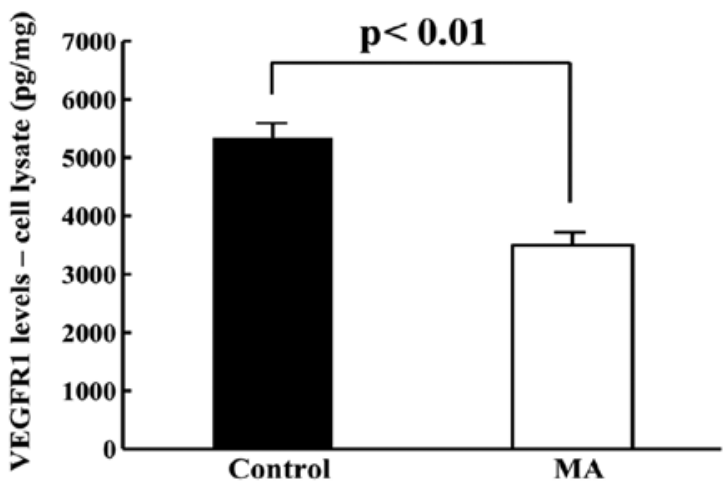

D

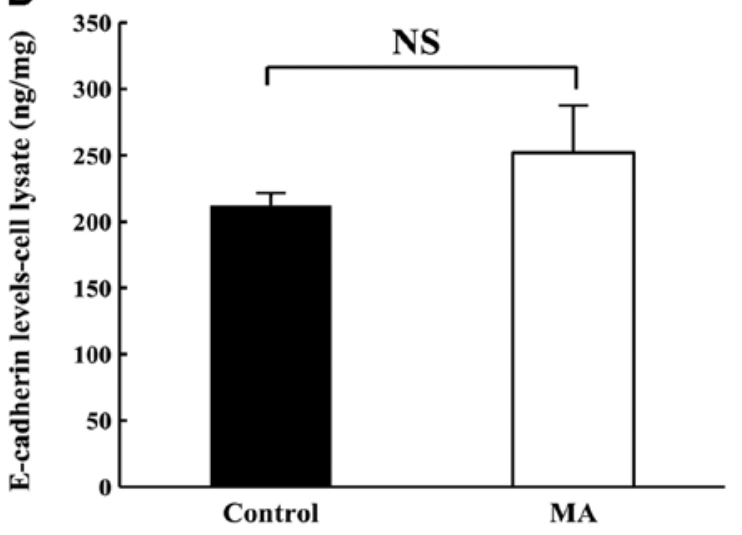

Figure 11. Effects of $\mathrm{IC}_{50}$ dose of mead acid (MA, $214.2 \mu \mathrm{M}$ ) for $72 \mathrm{~h}$ on changes in levels of (A) VEGF, (B) VEGFR1, (C) VEGFR2 and (D) E-cadherin in cultured KPL-1 cells. Levels were quantified by enzyme-linked immunoabsorbent assay (ELISA). Data are the means \pm SEM of 3 independent experiments. MA significantly lowered VEGFR1 and VEGFR2 levels, while VEGF and E-cadherin levels were similar. Data are the means \pm SEM of 3 independent experiments.

VEGFR1 and VEGFR2 expression tended to diminish and E-cadherin expression tended to increase in KPL-1 cells treated with the $\mathrm{IC}_{50}$ dose of MA for $72 \mathrm{~h}(214.2 \mu \mathrm{M})$ (Fig. 10).

Quantification of VEGF, VEGFR1, VEGFR2 and E-cadherin levels in KPL-1 cells in culture. Levels of VEGF, VEGFR1,
VEGFR2 and E-cadherin in KPL-1 cells cultured with or without the $\mathrm{IC}_{50}$ dose of $\mathrm{MA}$ for $72 \mathrm{~h}$ were compared. Although the VEGF levels in KPL-1 tumor cells were similar (Fig. 11A), MA treatment significantly decreased VEGFR1 and VEGFR2 levels and tended to increase E-cadherin levels (Fig. 11B-D). 


\section{Discussion}

In the present study, MA suppressed KPL-1 human breast cancer cell growth in culture with an $\mathrm{IC}_{50}$ value of $214.2 \mu \mathrm{M}$ $(65.7 \mu \mathrm{g} / \mathrm{ml})$ for $72 \mathrm{~h}$ and significantly suppressed KPL-1 tumor growth and regional (axillary) lymph node metastasis in female athymic mice. Tumor suppression was due to decreased cell proliferation. The body weight of the MA diet group, although it was similar to the control diet-fed mice at the termination of the present study, was significantly lighter during the experimental period; the dose of food intake was less in the MA-fed mice. Thus, the lighter body weight in the MA diet group may be due to consuming a low amount of the MA diet. The serum MA level in MA diet-fed mice was $237.2 \mu \mathrm{g} / \mathrm{ml}$, which is higher than the $\mathrm{IC}_{50}$ value. Thus, the $\mathrm{IC}_{50}$ dose of MA used in the in vitro experiments is achievable and may not cause serious side-effects in female mice. In contrast to n-3 PUFA, which invariably exerts antiproliferation action on human tumor cell lines, the n-9 series of MA causes different actions on different human tumor cells, depending on their origin and cellular types $(21,22)$. MA may function in a cell-specific manner. However, in agreement with MCF-7 human breast cancer cells, the MA diet suppressed KPL-1 tumor growth and metastasis in female athymic mice. Tumor growth is a balance between cell proliferation and cell death. Mammary tumors of the VEGF knockout mice exhibit cellcycle arrest and induction of apoptosis (37). With the present dose of MA, the MA diet suppressed KPL-1 tumor growth cytostatically by diminishing cell proliferation; however, it was below the dose needed to cause apoptosis.

Tumor angiogenesis is closely related to the growth of breast cancer, and VEGF and its receptors are essential for breast cancer growth (18-20). Cartilage is an avascular tissue and contains high levels of MA; MA dose-dependently inhibits VEGF-stimulated angiogenesis (17). However, MA did not alter angiogenesis as evaluated by microvessel density in KPL-1 tumors in athymic female mice. Although VEGF is well known for its key roles in blood vessel growth, it also promotes a range of other functions, such as cell adhesion, survival, migration and invasion (40). VEGF, VEGFR1 and VEGFR2 were immunohistochemically detected in KPL-1 cells. The presence of VEGFR1 and VEGFR2 as well as VEGF on KPL-1 cells may raise the possibility that VEGF may promote tumor growth not only by inducing angiogenesis but directly through the activation of VEGFR1 and VEGFR2 (41-43). In the present study, VEGF levels in cultured KPL-1 cells treated with MA were comparable to the levels in KPL-1 cells without MA treatment. However, VEGFR1 and VEGFR2 levels were significantly decreased in KPL-1 cells treated with MA. As VEGF, VEGFR1 and VEGFR2 were co-localized in KPL-1 cells, the present results suggest that VEGF signaling did not modulate angiogenesis, however it directly modulated the growth of VEGFR-positive tumor cells via an autocrine process, an endothelial cell-independent pathway (44). Expression of VEGF and its receptors (VEGF1 and VEGFR2) is associated with poor outcome in breast cancer patients (45). VEGF knockout directly decreases the proliferation of breast cancer cells (37).

Downregulation of E-cadherin is associated with loss of cellular adhesiveness and initiates metastatic outgrowth resulting in poor prognosis $(46,47)$. Downregulation of
E-cadherin is required to initiate metastatic outgrowth of breast cancer (47). VEGF increases transcription factor Snail, which is associated with breast cancer metastasis and reduces E-cadherin expression in breast cancer cells (48). Although MA tended to increase E-cadherin levels, the difference did not reach statistical significance. VEGF increases the cellular invasion of T-47D breast cancer cells on Matrigel/fibronectincoated transwell membranes (41). Therefore, VEGF, but not E-cadherin, may contribute to the mechanisms of suppression of invasion and metastasis in the KPL-1 tumor system.

In addition to affecting the VEGF pathway, MA may function via other unknown mechanisms. In a human case-control study of breast fat tissues, increased n-6/n-3 PUFA ratios and decreased n-3 PUFA levels were found in breast cancer patients as compared with controls $(49,50)$. Alteration in the n-6/n-3 PUFA ratio appears to be important (51) and n-3 PUFA, namely EPA and DHA (4) or n-6 PUFA, such as LA and AA $(11,12)$, is important. The MA diet-fed mice had significantly decreased LA and AA levels, and the n-6/n-3 PUFA ratio was significantly decreased in both the sera and the KPL-1 tumors, which may lead to growth suppression of KPL-1 cells. The essential fatty acid LA cannot be synthesized in the body and must be derived from the diet. Dietary LA shows a negative effect on the incorporation of dietary MA into the plasma lipid fraction and membrane phospholipids (52). LA is converted via intermediates to dihomo- $\gamma$-linolenic acid and to AA. Thus, an inverse relationship between n-9 PUFA MA and n-6 PUFA LA and AA may exist. In the present MA diet, decreased expression of n-6 PUFA, namely LA and AA, in the MA-fed mice, may suppress breast cancer cell proliferation and invasion (4). However, n- 6 content in the control diet was considerably below 4\%; n-6 PUFA (LA) at a dose of $\sim 4 \%$ is required for maximal acceleration of mammary tumorigenesis (53).

In conclusion, MA effectively suppressed the growth and metastasis of KPL-1 human breast cancer cells via VEGF signaling.

\section{Acknowledgements}

The authors thank Ms. S Takebe (University of Toyama) for her technical assistance and Ms. A Shudo (Kansai Medical University) for manuscript preparation. This study was supported in part by a Grant-in-Aid for Scientific Research (C) (24592611) from the Ministry of Education, Culture, Sports, Science and Technology of Japan, and by a grant from the Kiyoko Wada Foundation of the Kansai Medical University Alumni Association (2012).

\section{References}

1. Adami HO, Signorello LB and Trichopoulos D: Towards an understanding of breast cancer etiology. Semin Cancer Biol 8: 255-262, 1998 .

2. Tsubura A, Uehara N, Kiyozuka Y and Shikata N: Dietary factors modifying breast cancer risk and relation to time of intake. J Mammary Gland Biol Neoplasia 10: 87-100, 2005.

3. Tsubura A, Yuri T, Yoshizawa K, Uehara N and Takada H: Role of fatty acids in malignancy and visual impairment: epidemiological evidence and experimental studies. Histol Histopathol 24: 223-234, 2009.

4. Chénais B and Blanckaert V: The Janus face of lipids in human breast cancer: how polyunsaturated fatty acids affect tumor cell hallmarks. Int J Breast Cancer 2012: 712536, 2012. 
5. de Lorgeril M and Salen P: New insights into the health effects of dietary saturated and omega- 6 and omega- 3 polyunsaturated fatty acids. BMC Med 10: 50, 2012.

6. Bartsch H, Nair J and Owen RW: Dietary polyunsaturated fatty acids and cancers of the breast and colorectum: emerging evidence for their role as risk modifiers. Carcinogenesis 20: 2209-2218, 1999.

7. Yuri T, Danbara N, Tsujita-Kyutoku M, Fukunaga K, Takada H, Inoue Y, Hada T and Tsubura A: Dietary docosahexaenoic acid suppresses N-methyl-N-nitrosourea-induced mammary carcinogenesis in rats more effectively than eicosapentaenoic acid. Nutr Cancer 45: 211-217, 2003.

8. Wen ZH, Su YC, Lai PL, Zhang Y, Xu YF, Zhao A, Yao GY, Jia CH, Lin J, Xu S, Wang L, Wang XK, Liu AL, Jiang Y, Dai YF and Bai XC: Critical role of arachidonic acid-activated mTOR signaling in breast carcinogenesis and angiogenesis. Oncogene 32: 160-170, 2013.

9. Patterson RE, Flatt SW, Newman VA, Natarajan L, Rock CL, Thomson CA, Caan BJ, Parker BA and Pierce JP: Marine fatty acid intake is associated with breast cancer prognosis. J Nutr 141: 201-206, 2011.

10. Signori C, El-Bayoumy K, Russo J, Thompson HJ, Richie JP, Hartman TJ and Manni A: Chemoprevention of breast cancer by fish oil in preclinical models: trials and tribulations. Cancer Res 71: 6091-6096, 2011.

11. Senzaki H, Iwamoto S, Ogura E, Kiyozuka Y, Arita S, Kurebayashi J, Takada H, Hioki K and Tsubura A: Dietary effects of fatty acids on growth and metastasis of KPL-1 human breast cancer cells in vivo and in vitro. Anticancer Res 18: 1621-1627, 1998.

12. Chang NW, Wu CT, Chen DR, Yeh CY and Lin C: High levels of arachidonic acid and peroxisome proliferator-activated receptoralpha in breast cancer tissues are associated with promoting cancer cell proliferation. J Nutr Biochem 24: 274-281, 2013.

13. Taioli E, Nicolosi A and Wynder EL: Dietary habits and breast cancer: a comparative study of United States and Italian data. Nutr Cancer 16: 259-265, 1991.

14. Cohen LA, Epstein M, Pittman B and Rivenson A: The influence of different varieties of olive oil on N-methylnitrosourea (NMU)-induced mammary tumorigenesis. Anticancer Res 20 2307-2312, 2000.

15. Rose DP: Dietary fatty acids and cancer. Am J Clin Nutr 66 (Suppl 4): 998S-1003S, 1997.

16. Hamazaki T, Suzuki N, Widyowati R, Miyahara T, Kadota S, Ochiai $\mathrm{H}$ and Hamazaki K: The depressive effects of 5,8,11-eicosatrienoic acid (20:3n-9) on osteoblasts. Lipids 44: 97-102, 2009.

17. Hamazaki T, Nagasawa T, Hamazaki $\mathrm{K}$ and Itomura $\mathrm{M}$ : Inhibitory effect of 5,8,11-eicosatrienoic acid on angiogenesis Prostaglandins Leukot Essent Fatty Acids 86: 221-224, 2012.

18. Hicklin DJ and Ellis LM: Role of the vascular endothelial growth factor pathway in tumor growth and angiogenesis. J Clin Oncol 23: 1011-1027, 2005.

19. Fox SB, Generali DG and Harris AL: Breast tumour angiogenesis. Breast Cancer Res 9: 216, 2007.

20. Sharma PS, Sharma R and Tyagi T: VEGF/VEGFR pathway inhibitors as anti-angiogenic agents: present and future. Curr Cancer Drug Targets 11: 624-653, 2011 .

21. Eynard AR, Jiang WG and Mansel RE: Eicosatrienoic acid (20:3 n-9) inhibits the expression of E-cadherin and desmoglein in human squamous cell carcinoma in vitro. Prostaglandins Leukot Essent Fatty Acids 59: 371-377, 1998.

22. Heyd VL and Eynard AR: Effects of eicosatrienoic acid (20:3 n-9, Mead's acid) on some promalignant-related properties of three human cancer cell lines. Prostaglandins Other Lipid Mediat 71: $177-188,2003$

23. Jones $\mathbf{J}$ and Walker R: Cell-cell and cell-stromal interactions in breast cancer invasion and metastasis. Int J Oncol 11: 609-616, 1997.

24. Scully OJ, Bay BH, Yip G and Yu Y: Breast cancer metastasis. Cancer Genomics Proteomics 9: 311-320, 2012.

25. Pidgeon GP, Lysaght J, Krishnamoorthy S, Reynolds JV, O'Byrne K, Nie D and Honn KV: Lipoxygenase metabolism: roles in tumor progression and survival. Cancer Metastasis Rev 26: 503-524, 2007

26. Hu N, Li Y, Zhao Y, Wang Q, You JC, Zhang XD and Ye LH: A novel positive feedback loop involving FASN/p-ERK1/2/5-LOX/ LTB4/FASN sustains high growth of breast cancer cells. Acta Pharmacol Sin 32: 921-929, 2011.
27. James MJ, Gibson RA, Neumann MA and Cleland LG: Effect of dietary supplementation with n-9 eicosatrienoic acid on leukotriene $\mathrm{B}_{4}$ synthesis in rats: a novel approach to inhibition of eicosanoid synthesis. J Exp Med 178: 2261-2265, 1993.

28. Cleland LG, Gibson RA, Neumann MA, Hamazaki T, Akimoto K and James MJ: Dietary (n-9) eicosatrienoic acid from a cultured fungus inhibits leukotriene $\mathrm{B}_{4}$ synthesis in rats and the effect is modified by dietary linoleic acid. J Nutr 126: 1534-1540, 1996.

29. Pouchieu C, Chajès V, Laporte F, Kesse-Guyot E, Galan P, Hercberg S, Latino-Martel P and Touvier M: Prospective associations between plasma saturated, monounsaturated and polyunsaturated fatty acids and overall and breast cancer risk modulation by antioxidants: a nested case-control study. PLoS One 9: e90442, 2014.

30. Kurebayashi J, Kurosumi M and Sonoo H: A new human breast cancer cell line, KPL-1 secretes tumour-associated antigens and grows rapidly in female athymic nude mice. Brit J Cancer 71: 845-853, 1995 .

31. Kurebayashi J, Kanomata N, Moriya T, Kozuka Y, Watanabe M and Sonoo H: Preferential antitumor effect of the Src inhibitor dasatinib associated with a decreased proportion of aldehyde dehydrogenase 1-positive cells in breast cancer cells of the basal B subtype. BMC Cancer 10: 568, 2010.

32. Kanematsu S, Uehara N, Miki H, Yoshizawa K, Kawanaka A, Yuri T and Tsubura A: Autophagy inhibition enhances sulforaphane-induced apoptosis in human breast cancer cells. Anticancer Res 30: 3381-3390, 2010.

33. No authors listed: Report of the American Institute of Nutrition Ad Hoc Committee on Standards for Nutritional Studies. J Nutr 107: 1340-1348, 1977.

34. Sakuradani E, Kamada N, Hirano Y, Nishihara M, Kawashima H, Akimoto K, Higashiyama K, Ogawa J and Shimizu S: Production of $5,8,11$-eicosatrienoic acid by a $\Delta 5$ and $\Delta 6$ desaturation activity-enhanced mutant derived from a $\Delta 12$ desaturation activity-defective mutant of Mortierella alpina 1S-4. Appl Microbiol Biotechnol 60: 281-287, 2002.

35. Bligh EG and Dyer WJ: A rapid method of total lipid extraction and purification. Can J Biochem Physiol 3: 911-917, 1959.

36. Lai YC, Hamazaki K, Yoshizawa K, Kawanaka A, Kuwata M, Kanematsu S, Hamazaki T, Takada $\mathrm{H}$ and Tsubura A: Short-term pregnancy hormone treatment of $N$-methyl- $N$-nitrosoureainduced mammary carcinogenesis in relation to fatty acid composition of serum phospholipids in female Lewis rats. In Vivo 24: 553-560, 2010.

37. Schoeffner DJ, Matheny SL, Akahane T, Factor V, Berry A, Merlino $\mathrm{G}$ and Thorgeirsson UP: VEGF contributes to mammary tumor growth in transgenic mice through paracrine and autocrine mechanisms. Lab Invest 85: 608-623, 2005.

38. Kanematsu S, Yoshizawa K, Uehara N, Miki H, Sasaki T, Kuro M, Lai YC, Kimura A, Yuri T and Tsubura A: Sulforaphane inhibits the growth of KPL-1 human breast cancer cells in vitro and suppresses the growth and metastasis of orthotopically transplanted KPL-1 cells in female athymic mice. Oncol Rep 26: 603-608, 2011

39. Redon CE, Weyemi U, Parekh PR, Huang D, Burrell AS and Bonner WM: $\gamma-\mathrm{H} 2 \mathrm{AX}$ and other histone post-translational modifications in the clinic. Biochim Biophys Acta 1819: 743-756, 2012.

40. Perrot-Applanat M and Di Benedetto M: Autocrine functions of VEGF in breast tumor cells: adhesion, survival, migration and invasion. Cell Adh Migr 6: 547-553, 2012.

41. Price DJ, Miralem T, Jiang S, Steinberg R and Avraham H: Role of vascular endothelial growth factor in the stimulation of cellular invasion and signaling of breast cancer cells. Cell Growth Differ 12: 129-135, 2001.

42. Weigand M, Hantel P, Kreienberg R and Waltenberger J: Autocrine vascular endothelial growth factor signalling in breast cancer. Evidence from cell lines and primary breast cancer cultures in vitro. Angiogenesis 8: 197-204, 2005.

43. Wu Y, Hooper AT, Zhong Z, Witte L, Bohlen P, Rafii S and Hicklin DJ: The vascular endothelial growth factor receptor (VEGFR-1) supports growth and survival of human breast carcinoma. Int J Cancer 119: 1519-1529, 2006.

44. Guo S, Colbert LS, Fuller M, Zhang Y and Gonzalez-Perez RR: Vascular endothelial growth factor receptor-2 in breast cancer. Biochim Biophys Acta 1806: 108-121, 2010.

45. Ghosh S, Sullivan CA, Zerkowski MP, Molinaro AM, Rimm DL, Camp RL and Chung GG: High levels of vascular endothelial growth factor and its receptors (VEGFR-1, VEGFR-2, neuropilin-1) are associated with worse outcome in breast cancer. Hum Pathol 39: 1835-1843, 2008. 
46. Howard EM, Lau SK, Lyles RH, Birdsong GG, Umbreit JN and Kochhar R: Expression of e-cadherin in high-risk breast cancer. J Cancer Res Clin Oncol 131: 14-18, 2005.

47. Wendt MK, Taylor MA, Schiemann BJ and Schiemann WP: Downregulation of epithelial cadherin is required to initiate metastatic outgrowth of breast cancer. Mol Biol Cell 22: 2423-2435, 2011.

48. Wanami LS, Chen HY, Peiró S, García de Herreros A and Bachelder RE: Vascular endothelial growth factor-A stimulates Snail expression in breast tumor cells: implications for tumor progression. Exp Cell Res 314: 2448-2453, 2008

49. Zhu ZR, Agren J, Männistö S, Pietinen P, Eskelinen M, Syrjänen $\mathrm{K}$ and Uusitupa M: Fatty acid composition of breast adipose tissue in breast cancer patients and in patients with benign breast disease. Nutr Cancer 24: 151-160, 1995.

50. Maillard V, Bougnoux P, Ferrari P, Jourdan ML, Pinault M, Lavillonnière $\mathrm{F}$, Body $\mathrm{G}$, Le Floch $\mathrm{O}$ and Chajès $\mathrm{V}$ : N-3 and N-6 fatty acids in breast adipose tissue and relative risk of breast cancer in a case-control study in Tours, France. Int J Cancer 98: 78-83, 2002.
51. Okuyama H, Kobayashi T and Watanabe S: Dietary fatty acids the $n-6 / n-3$ balance and chronic elderly diseases. Excess linoleic acid and relative n-3 deficiency syndrome seen in Japan. Prog Lipid Res 35: 409-457, 1996.

52. Cleland LG, Neumann MA, Gibson RA, Hamazaki T, Akimoto K and James MJ: Effect of dietary n-9 eicosatrienoic acid on the fatty acid composition of plasma lipid fractions and tissue phospholipids. Lipids 31: 829-837, 1996.

53. Ip C, Carter CA and Ip MM: Requirement of essential fatty acid for mammary tumorigenesis in the rat. Cancer Res 45 : 1997-2001, 1985. 